\title{
O jogo digital como estratégia para o ensino da história
}

\author{
The digital game as a strategy for the teaching of history
}

El juego digital como estrategia para o enseñanza de la historia

\author{
Roselene Moreira Gomes Pommer ${ }^{1}$ \\ Luana Lopes ${ }^{2}$
}

\begin{abstract}
Resumo
O presente trabalho pretende relatar a experiência de aplicação do jogo "Quiz Digital: sociedades sambaquianas", desenvolvido por estudantes do Curso de Mestrado Acadêmico em Educação Profissional e Tecnológica, como estratégia facilitadora para o processo de construção de conhecimentos históricos. A produção de um jogo digital de perguntas e respostas para a área de História aponta para as possibilidades de integração entre os conhecimentos da área de ciências humanas e aqueles conhecimentos gerados pelos componentes de áreas técnicas, como iniciação à programação, eletrônica e microeletrônica. A experiência didático pedagógica aqui discutida deu-se com alunos do $3^{\circ}$ semestre do Curso Técnico em Eletromecânica Integrado ao Ensino Médio na Modalidade Educação de Jovens e Adultos - PROEJA, do Colégio Técnico Industrial de Santa Maria, unidade vinculada a Universidade Federal homônima. Da atividade, resultaram avaliações e sugestões para o aprimoramento do jogo, dadas por alunos trabalhadores que, em geral, são tidos como imigrantes digitais, que somente após a popularização das novas tecnologias, vêm adotando-as gradativamente.
\end{abstract}

Palavras-chaves: Jogo Digital; Aprendizagem; Programação; História.

\begin{abstract}
This paper aims to report the game application "Digital Quiz: sambaquian societies" experience developed by students of the Academic Master in Professional Education and Technology, as a facilitator strategy for the process of construction of historical knowledge. The production of a digital game of questions and answers for the history area, for the possibilities of integration between the components of the humanities area and those related to the components of technical areas, such as initiation to program, eletronics and microeletronics. The experience took place with students from 3rd semester of the Technical Course in Integrated Electromechanical to high school in the Youth and Adult Education Mode - PROEJA, College of Industrial Technical Santa Maria, linked unit the Federal University homonymous. Activity resulted reviews and suggestions for the improvement of the game, given by students workers in general are regarded as digital immigrants, that only after the popularization of new technologies, have adopted them gradually.
\end{abstract}

Keywords: Digital Game; Learning; Programming; History.

\section{Resumen}

El presente trabajo pretende relatar la experiencia de aplicación del juego "Quiz Digital: sociedades sambaquianas", desarrollado por estudiantes del Curso de Maestría Académica en Educación Profesional y Tecnológica, como estrategia facilitadora para el proceso de construcción de conocimientos históricos. La producción de un juego digital de preguntas y respuestas para el área de Historia apunta a las posibilidades de integración entre los conocimientos del área de ciencias humanas y aquellos conocimientos generados por los componentes de áreas técnicas, como iniciación a la programación, electrónica y microelectrónica. La experiencia didáctica pedagógica aquí discutida se dio con alumnos del $3^{\circ}$ semestre del Curso Técnico en Electromecánica Integrado a la Enseñanza Media en la modalidad Educación de Jóvenes y Adultos - PROEJA, del Colegio Técnico Industrial de Santa María, unidad vinculada a la Universidad Federal homónima. De la

\footnotetext{
${ }^{1}$ Doutora em História - PPGEPT/UFSM; RS; Brasil; roselenepommer@ctism.ufsm.br

${ }^{2}$ Mestranda em Educação profissional e Tecnológica - PPGEPT/UFSM; RS; Brasil; luanalopesmk@gmail.com
} 
actividad, resultaron evaluaciones y sugerencias para el perfeccionamiento del juego, dadas por alumnos trabajadores que, en general, son tenidos como inmigrantes digitales, que sólo después de la popularización de las nuevas tecnologías, vienen adoptando gradualmente.

Palabras claves: Juego Digital; aprendizaje; programación; Historia.

\title{
1.Introdução
}

O presente artigo pretende relatar e analisar a produção e a aplicação de um jogo digital desenvolvido por estudantes do Curso de Mestrado Acadêmico em Educação Profissional e Tecnológica, do Programa de Pós-Graduação homônimo, do Colégio Técnico Industrial de Santa Maria (CTISM), unidade vinculada a Universidade Federal de Santa Maria (UFSM). O objetivo primeiro da produção do jogo intitulado QUIZ DIGITAL: SOCIEDADES SAMBAQUIANAS foi o de oferecer estratégias pedagógicas alternativas para o ensino da história. Além desse objetivo, pretendeu-se indicar as possibilidades de integração entre os conhecimentos da área de ciências humanas e aqueles conhecimentos gerados pelos componentes de áreas técnicas, como iniciação à programação, eletrônica e microeletrônica.

Comumente tem-se defendido que os indivíduos precisam aprender a aprender. Para Lombardi (2011) o homem é o único animal que necessita aprender, pois dessa aprendizagem depende a produção da sua existência. Para o autor (2011, p. 2013)

\begin{abstract}
o homem não nasce pronto, mas tem de tornar-se homem. Ele forma-se homem. Ele não nasce sabendo produzir-se como homem. Ele necessita aprender a ser homem, precisa aprender a produzir a sua própria existência. Portanto, a produção do homem é, ao mesmo tempo, a formação do homem, isto é um processo educativo. A origem da educação coincide, então, com a origem do homem mesmo.
\end{abstract}

A relação que o autor estabelece entre a educação e o trabalho onto-criativo deve-se ao fato de que a aprendizagem não acontece naturalmente, sua construção exige, no mínimo, três elementos que devem correlacionar-se: o objeto a ser conhecido, o sujeito cognoscente e a situação desafiadora que poderá, ou não, ser intermediada por alguém ou por algum recurso.

A necessidade de interação entre esses três elementos tem levado professores e pesquisadores a se preocuparem em oferecer, aos estudantes, estratégias motivadoras de produção e de ressignificação de conhecimentos. Hoje, mais do que em épocas anteriores, os estudantes têm trazido para os espaços formais de educação, experiências oriundas de universos caracterizados pelo dinamismo, o que é provocado pela intensidade e variedade de cores, sons e movimentos. Disso resulta o repensar sobre os ambientes estáticos que 
caracterizaram as salas de aula tradicionais, tidas como sem atrativos e desprovidas de sentido.

A questão é pertinente na medida em que, segundo Rufini et al (2012), a motivação do aluno reflete no seu desempenho escolar e na qualidade da sua aprendizagem. Já Barbosa (1998) vai além dessa constatação ao afirmar que é preciso buscar novas formas de estimular o interesse dos educandos pela aprendizagem, melhorando sua vinculação sócia afetiva com as situações de aprendizagem. Uma das propostas de superação dessas dificuldades foi feita por Tarouco (2005), que percebeu nos jogos de computadores, um importante recurso para a desejada motivação dos estudantes em relação as ações pedagógicas.

Assim, os jogos educacionais são considerados, hoje, ferramentas de aprendizagem eficientes, pois ao mesmo tempo em que promovem a diversão, também motivam, estimulando o interesse dos alunos para a construção de novos conhecimentos. Outra questão positiva envolvendo jogos educativos, em especial aqueles digitais, diz respeito ao exercício de funções mentais e intelectuais dos jogadores, ampliando e facilitando a capacidade de retenção e de ressignificação de conceitos e das relações desses com os conteúdos ministrados (Tarouco et al, 2004; Vilarinho e Leite, 2015).

Logo, os jogos educacionais são atraentes aos alunos na medida em que provocam algumas reações como: emoção, pois possuem história e representação; prazer e agitação, proporcionados pela liberação de adrenalina, que é estimulada pela competição; desafios e conflitos, entre outras (Tarouco, 2015) e, especialmente, interação e cooperação com/no grupo, o que implica positivamente, no processo de ensino e aprendizagem.

\section{O Jogo}

\subsection{Objetivos}

O objetivo principal do jogo QUIZ DIGITAL: SOCIEDADES SAMBAQUIANAS foi oferecer estratégias para que os estudantes compreendam o surgimento e a organização técnico-cultural dos agrupamentos humanos surgidos ao longo do litoral do espaço hoje identificado como Rio Grande do Sul, durante o período cenozóico. Pretendeu-se, também, situar através do jogo, o papel do homem no processo de transformação da natureza, dimensionando, para além do tempo presente, os limites e o poder das ações antrópicas sobre o espaço natural. 
A utilização da imagem de dinossauros como plano de fundo da tela do jogo e dos cartões, se deve a necessidade de superação da ideia produzida pelo senso comum e fomentada pelas produções midiáticas e cinematográficas, de que homens e dinossauros teriam convivido em um mesmo tempo histórico. Também a utilização desse tipo de imagem pretende atrair a atenção dos jogadores, pois sempre desperta o interesse para um tempo considerado perdido, objeto de muitos romances e escritos famosos e que tem tido muita aderência entre jovens e crianças.

\subsection{Dinâmicas}

A aplicação do jogo dá-se a partir da seguinte dinâmica:

$\checkmark$ Organização dos estudantes em dois grupos, um intitulado azul, outro vermelho.

$\checkmark$ O professor com um computador e um Datashow, media a atividade.

$\checkmark$ Cada grupo recebe dez cartões contendo respostas aleatórias.

$\checkmark$ O professor sorteia o grupo que iniciará o jogo.

$\checkmark$ O professor conecta o leitor de respostas na porta USB, abre o jogo no computador e seleciona a porta serial para inicializar o leitor de respostas. Após, seleciona o grupo que dará início ao jogo.

$\checkmark$ O professor, por meio do computador, clica no botão "Respostas", selecionando aleatoriamente uma pergunta, a qual a visualizada por todos no projetor.

$\checkmark$ Os alunos escolhem uma carta resposta. Após a escolha, um dos alunos do grupo se dirige ao leitor de respostas, aproximando o cartão com a resposta que considera correta, visualizada por todos através do Datashow.

$\checkmark$ Se a resposta estiver correta, o grupo conquista um ponto e prossegue o jogo.

$\checkmark$ Se a respostas não estiver correta, o grupo perde um ponto, o professor oferece uma dica e o grupo passa outra carta no leitor, até acertar a pergunta.

$\checkmark$ Se após 05 dicas, nenhum dos grupos acertar a resposta, o professor indica-a.

$\checkmark$ Considera-se vencedor o grupo que obtiver a maior quantidade de pontos.

Portanto, o jogo se caracteriza por perguntas e respostas que envolvem conhecimentos a respeito das sociedades sambaquianas. Deve ser aplicado após o estudo, discussão e reflexão sobre a temática e serve, fundamentalmente, para a construção, revisão e ressignificação de conceitos históricos, como sambaquis, arte rupestre, materiais líticos e conhecimentos técnicos, identificando as rupturas e as permanências culturais humanas ao longo dos processos históricos. Sua faixa etária de aplicação envolve estudantes com idades 
em torno de doze anos, sendo indicado para a correlação com os conteúdos do $5^{\circ}$ e do $6^{\circ}$ anos do Ensino Fundamental.

\subsection{Produção}

A produção do jogo foi o resultado da ação associativa de professores e de estudantes cujas áreas possuem objetos de pesquisa distintos, ou seja, história (ciências humanas), informática, desenho industrial e eletrônica (ciências exatas). A sutura responsável pela articulação de profissionais de áreas diferentes, foi representada pela percepção da necessidade de estratégias motivadoras de aprendizagem. Dessa articulação entre partes aparentemente diferentes entre si, deu-se o surgimento do novo, ou seja, de uma ação pedagógica inovadora.

Tecnicamente, a produção de jogos educacionais digitais envolvem software e hardware. Para sua produção, é preciso, inicialmente escolher os recursos técnicos que serão empregados. Estes incluem, por exemplo, o sistema operacional que rodará o software, as linguagens e ambientes de programação (IDE), os micro controladores e os componentes eletrônicos, como leitores e cartões de identificação por radiofrequência (RFID).

Para o desenvolvimento do software que envolveu o jogo QUIZ DIGITAL: SOCIEDADES SAMBAQUIANAS (Figura 1), o sistema operacional escolhido foi o Windows Seven ou posterior, desenvolvido pela Microsoft. A escolha deu-se pelo fato deste ser um sistema operacional simples, o que o torna um dos mais utilizados pelos usuários. A opção pelas linguagens de programação C\#, NET e o IDE Microsoft Visual Studio 2015, deveu-se a robustez, a interface amigável e a compatibilidade com o sistema operacional Windows.

Pensando-se na facilidade de leitura posterior por parte de outros programadores e pela portabilidade para outras linguagens de programação, o algoritmo do jogo foi desenvolvido de forma estruturada. 
RELACult - Revista Latino-Americana de Estudos em Cultura e Sociedade

Revista Latinoamericana de Estudios en Cultura y Sociedad | Latin American Journal of Studies in Culture and Society V. 05, ed. especial, abr., 2019, artigo no 1190| claec.org/relacult | e-ISSN: 2525-7870

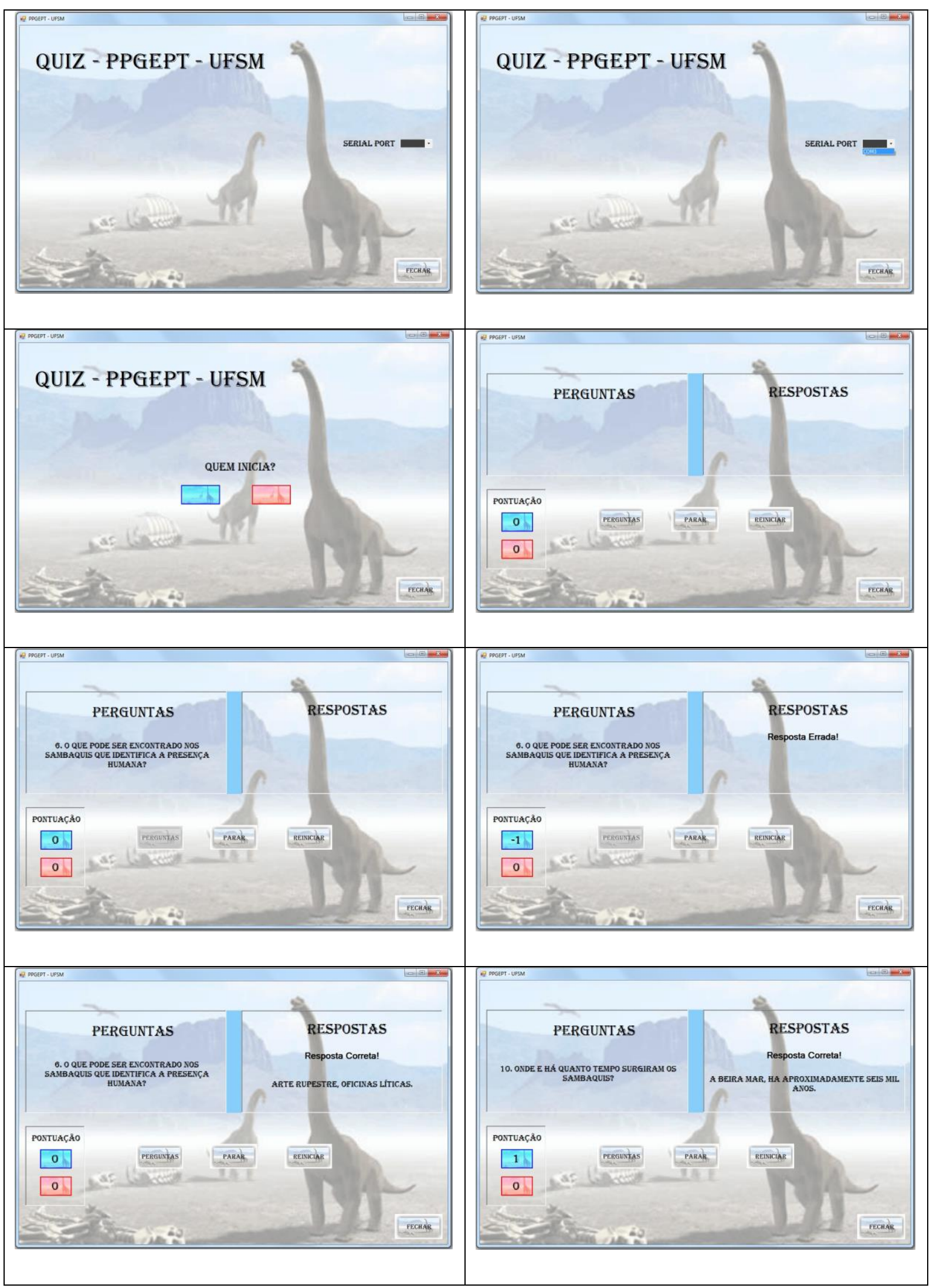


RELACult - Revista Latino-Americana de Estudos em Cultura e Sociedade

Revista Latinoamericana de Estudios en Cultura y Sociedad | Latin American Journal of Studies in Culture and Society V. 05, ed. especial, abr., 2019, artigo $n^{\circ}$ 1190| claec.org/relacult | e-ISSN: 2525-7870

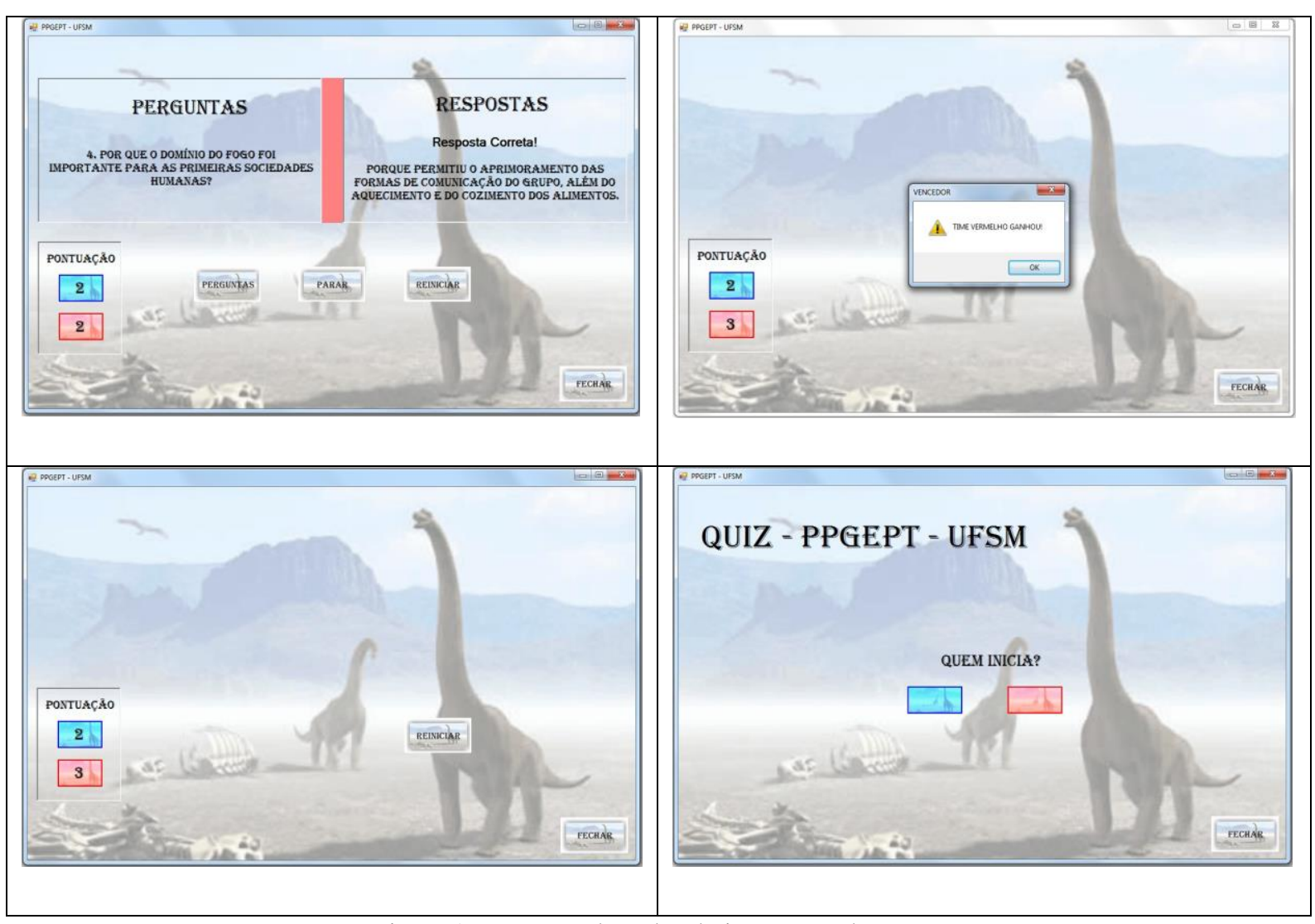

Figura 1 - Imagem das telas do jogo. Foto dos autores.

\section{O Hardware}

\subsection{Leitor de Cartões RFID}

O hardware (Figura 2) é composto de uma placa microcontrolada Arduino Mega 2560, um leitor de cartão RFID MFRC522 da empresa NXP, que trabalha com uma frequência de 13,56MHz, uma placa protoboard, um cabo USB para ligar ao computador, jumpers e uma caixa de papelão.

O algoritmo da placa Arduino foi desenvolvido utilizando-se o modelo de programação estruturada, cuja linguagem de foi a $\mathrm{C} / \mathrm{C}++$ e a IDE ARDUINO 1.6.3 da Equipe Arduino. 


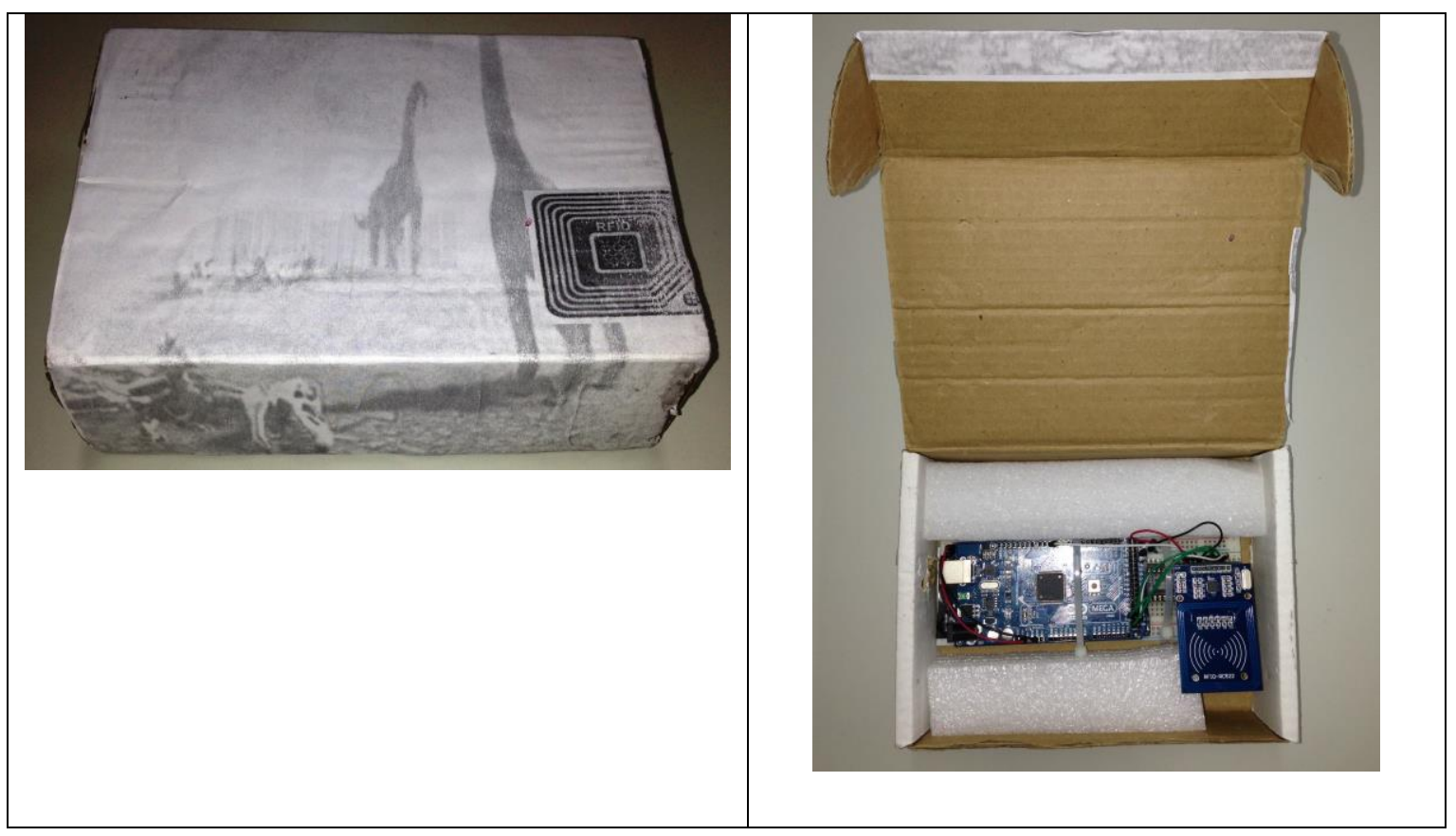

Figura 2 - Imagens do leitor de cartões RFID. Foto dos autores.

\subsection{Cartões de resposta RFID}

Os cartões respostas (Figura 3) totalizam 20, sendo 10 para o grupo azul e 10 para o grupo vermelho. Os Cartão são do tipo RFID Programável Mifare 13,56Mhz e possuem um número de identificação (UID) pré-gravado e memória de 1KB para armazenagem dos dados. Para esse trabalho foi utilizado o UID pré-gravado no cartão. No entanto, posteriormente, poderá ser gravado um novo UID, de acordo com novas necessidades operacionais do jogo.

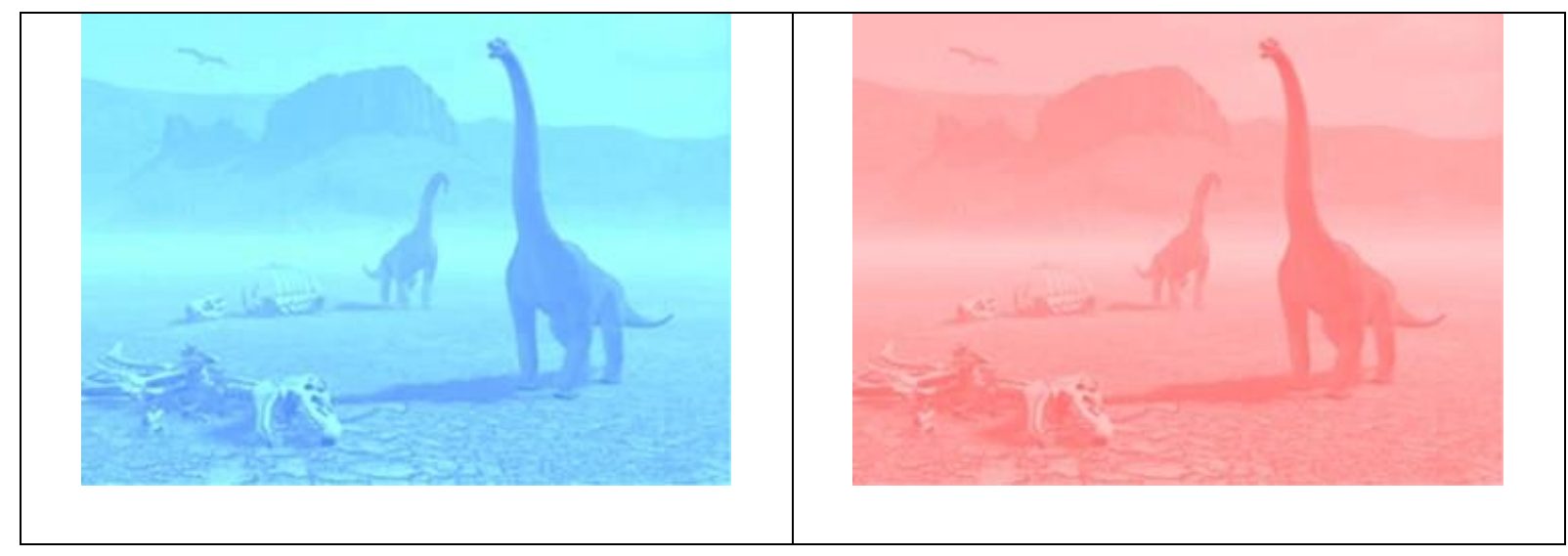




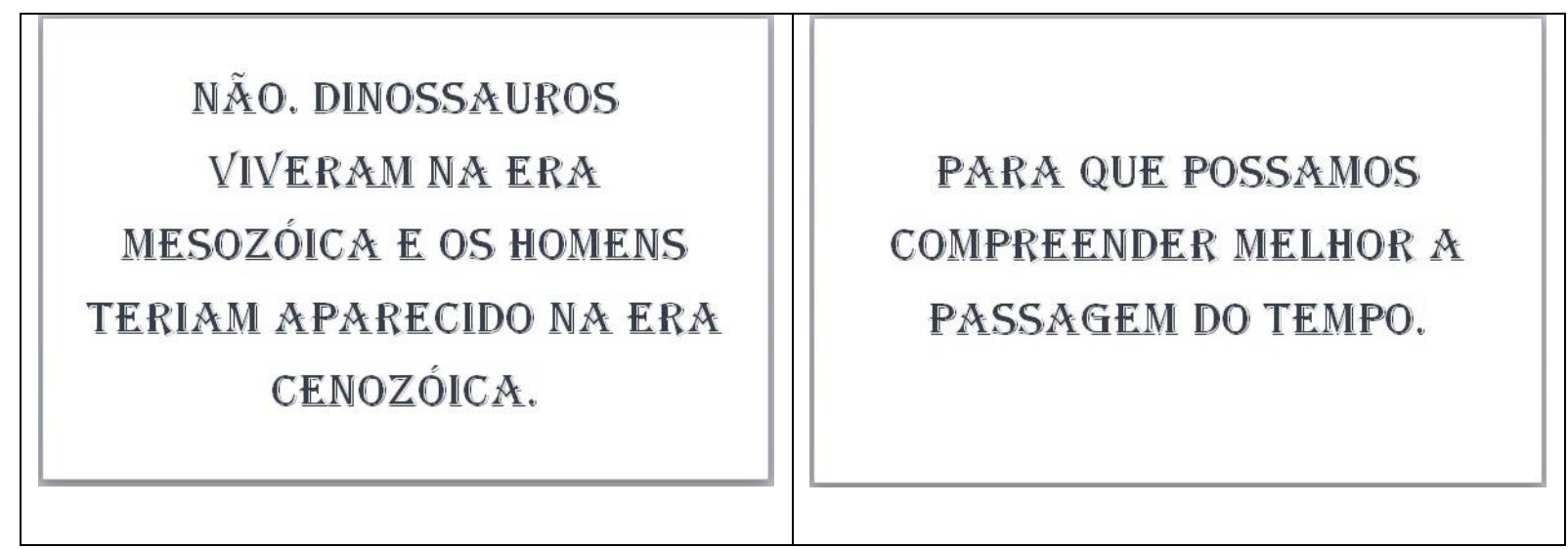

Figura 3 - Imagens do fundo dos cartões azul e vermelho e duas imagens frontais com as respostas. Foto dos autores.

\subsection{A Aplicação}

O jogo foi projetado para ser aplicado junto a estudantes dos $5^{\circ}$ e $6^{\circ}$ anos do Ensino Fundamental. Entretanto, em função dos conhecimentos técnicos que envolveram sua produção, optou-se por experimentá-lo com estudantes de cursos técnicos profissionalizantes. Esse fato levou a sua aplicação junto a turma de terceiro semestre do Curso Técnico em Eletromecânica Integrado ao Ensino Médio na Modalidade Educação de Jovens e Adultos PROEJA, do CTISM e compôs, juntamente com outras atividades, uma oficina para estudantes já inseridos no mundo do trabalho. Pretendeu-se, com isso, estimular os sujeitos a perceberem a importância da cultura dos povos originários para a constituição das identificações regionais do Estado do Rio Grande do Sul, o que, muitas vezes, se evidencia nos ambientes de trabalho.

A atividade contou, também, com a utilização de um jogo de tabuleiro, bem como de explicações acerca das culturas dos povos originários da América do Sul a partir do uso de duas maquetes, sendo uma específica sobre a dinâmica da sociedade sambaquiana. Inicialmente foram apresentados e discutidos com os estudantes, os conhecimentos que seriam necessários para o desenvolvimento do jogo digital. Na sequência, organizaram-se dois grupos de cinco alunos cada, iniciando-se a sessão.

\section{Resultados Alcançados}

Em "Filosofia da Caixa Preta", Vilém Flusser afirma que "Não é a madeira do tabuleiro e das pedras que torna o xadrez um jogo. São as virtualidades contidas nas regras: o software" (2002: 27). Ou seja, são os aspectos impalpáveis e simbólicos os portadores de valor para as sociedades da Revolução Tecnológica e Informacional. 
É nesse âmbito que o uso de jogos digitais contribui para "potencializar a aprendizagem num contexto tecnológico em evolução e, no âmbito da História, promover o desenvolvimento de ideias de segunda ordem, como causa, evidência ou empatia histórica" (CARVALHO, \& PENICHEIRO, 2009, s/p).

Pois foi esse elemento que se procurou referenciar nesse jogo digital. Tanto mais para um jogo que envolveu conhecimentos de história, ele se mostrou eficaz ao permitir a abstração dos elementos do passado das sociedades sambaquianas. A sua aplicação em turmas de alunos trabalhadores foi pertinente, dinamizou a processo de aprendizagem e permitiu a ressignificação de noções e comportamentos pré-concebidos em relação aos povos indígenas.

$\mathrm{Na}$ avaliação dos estudantes, essa foi "uma aula de história diferente, que além de apresentar conhecimentos sobre os povos indígenas, ofereceu chances de usar conhecimentos de eletrônica, envolvendo magnetismo elétrico” (Estudante A); “(...) além de aprendermos sobre povos indígenas e sua herança cultural, também podemos (sic) nos aproximar de outras áreas de ensino, já que os jogos exigem conhecimentos de programação e eletrônica" (Estudante B); “(...) tivemos uma aula com um diferencial, uma boa dinâmica, muito interessante, bem executada e muito bem recebida por nós alunos" (Estudante C).

A aplicação serviu, também, para a percepção da necessidade de ajustes do instrumento, como a adição de um limitador de tempo para as apresentações das respostas, bem como, de um sinalizador sonoro para a marcação daquelas corretas e a alternância das perguntas entre os grupos.

Muito embora a lei 11.645/08 tenha exigido das escolas de formação básica o estudo da história e da cultura indígena, além da africana e afro-brasileira, a atividade atendeu aos objetivos propostos ao dinamizar o processo pedagógico e promover a interação e integração entre os estudantes.

\section{Conclusão}

A aplicação de jogos é efetivamente um meio eficaz de utilização dos chamados objetos de aprendizagem. Eles possibilitam despertar a atenção do aluno, bem como a sua sensibilização, facilitando a avaliação do processo de ensino/aprendizagem e permitindo ao educador perceber se os objetivos propostos foram alcançados. Além disso, torna o ambiente da sala de aula descontraído e contribui para a superação de barreiras entre o educador e os educandos, na medida em que o professor se coloca como mediador, conciliador nas diversas situações surgidas durante a aplicação do jogo. Neste contexto, o mediador interpreta e auxilia 
na aplicação das regras do jogo, orienta o momento em que cada jogador ou equipe deve fazer a jogada, ratifica a resposta certa ou errada e a pontuação a partir do registro apontado na tela.

No momento em que surgem dúvidas sobre o conteúdo, o mediador assume o papel de educador e introduz elementos de conhecimento que não se encontram diretamente envolvidos no jogo, mas que servem para agregar novos elementos ao processo de aprendizagem.

O potencial do jogo digital a partir dessa proposta está também, no fato dele possibilitar a interação de sujeitos que são frutos de dois diferentes universos de experiências: aquele dos estudantes adultos trabalhadores, tidos como imigrantes digitais e que somente após a popularização das novas tecnologias, vêm adotando-as gradativamente, e aquele dos estudantes jovens, os nativos digitais, nascidos e crescidos em um mundo no qual as novas mídias tornaram o acesso ao conhecimento rápido e fácil.

\section{Referências}

BARBOSA, L. Projeto de trabalho: uma forma de atuação psicopedagógica. $2^{\mathrm{a}}$ ed. Curitiba: L. M. S, 1998.

FLUSSER, V. Filosofia da Caixa Preta. Rio de Janeiro: Relume Dumará, 2002.

RUFINI, S. E.; BZUNECK, J. A.; OLIVEIRA, K. L. D. A Qualidade da Motivação em Estudantes do Ensino Fundamental. Paidéia, Curitiba, v. 22, n. 51, p. 53-62. 2012.

TAROUCO, L. Jogos, computador e Internet na educação. Disponível em: http://penta3.ufrgs.br/animacoes/JogosEducacionais> Acesso: 26 de novembro de 2015.

TAROUCO, L. M. R.; ROLAND, L. C.; FABRE, M. C. J. M.; KONRATH, M. L. P. Jogos educacionais, RENOTE - Novas Tecnologias na Educação, v. 2, n. 1. 2004.

VILARINHO, L. R. G.; LEITE, M. P. AVALIAÇÃO DE JOGOS ELETRÔNICOS PARA USO NA PRÁTICA PEDAGÓGICA: ULTRAPASSANDO A ESCOLHA BASEADA NO BOM SENSO, RENOTE - Novas Tecnologias na Educação, v. 13, n. 1. 2015. 